\title{
Hepatic arterial infusion in colorectal carcinoma: is anatomical targeting still relevant in an era of molecularly targeted therapy?
}

\author{
Bohuslav Melichar
}

Background. Historically, metastatic colorectal carcinoma was regarded as a tumor that is relatively resistant to cytotoxic agents. Due to the limited number of treatment options, methods have been investigated to enhance selectivity. One method for enhancing selectivity is anatomical targeting, including hepatic arterial infusion (HAI).

Methods. A comprehensive review of the literature.

Results. Early studies with HAl used fluoropyrimidines, 5-fluorouracil or floxuridine. Several randomized trials comparing the HAl of fluoropyrimidines with systemic administration of fluoropyrimidines or best supportive care that were conducted in the 1980s and early 1990 s demonstrated a superior objective response rate, but usually not a prolongation of survival in patients treated with HAl. The current standard of first line systemic chemotherapy of metastatic colorectal carcinoma is combination chemotherapy (fluoropyrimidines, oxaliplatin and/or irinotecan) administered with targeted agents. A number of trials have reported promising activity of the HAI of oxaliplatin and/or irinotecan with fluoropyrimidines, but only pilot studies are available for the combination of HAl of cytotoxic agents with targeted drugs. Factors that limit the effectiveness and utilization of HAl include catheter or port system-related complications, the presence of extrahepatic metastases, or increased risk of hepatic toxicity.

Conclusions. HAl could be considered in clinical practice in different settings, including patients after liver resection, as second line therapy in patients failing standard front line regimens and as neodjuvant therapy to convert to resectability. Future studies should specifically concentrate on identifying regimens that would result in increased cure rates in patients with isolated hepatic metastases. For this reason, exploiting anatomical selectivity may still be a useful approach, even in the era of targeted therapy.

Key words: 5-fluorouracil, colorectal carcinoma, floxuridine, hepatic arterial infusion, irinotecan, oxaliplatin

Received: December 12, 2011; Accepted: April 12, 2012; Available online: June 1, 2012

http://dx.doi.org/10.5507/bp.2012.047

Department of Oncology, Faculty of Medicine and Dentistry, Palacky University Olomouc, Czech Republic Corresponding author: Bohuslav Melichar, e-mail: bohuslav.melichar@fnol.cz

\section{INTRODUCTION}

Colorectal carcinoma is one of the most frequent malignant tumors and also one of the leading causes of cancer mortality. An overwhelming majority of colorectal carcinoma deaths are caused by uncontrolled growth of metastases. These metastases are either present at the time of diagnosis or develop later during the course of follow up. Surgery is the mainstay of therapy in localized colorectal carcinoma. However, in patients with metastatic disease the utilization of surgery is limited to a subgroup of patients with resectable (usually liver or lung) metastases, and even in this selected subgroup surgical resection is usually not curative.

Chemotherapy is the principal therapeutic modality in patients with metastatic colorectal carcinoma. Historically, colorectal carcinoma has been resistant to most cytotoxic agents. During the last 20 years, we have witnessed considerable progress in the chemotherapy of colorectal carcinoma. After demonstration that fluoropyrimidine-based chemotherapy significantly prolongs survival in patients with metastatic colorectal carcinoma $^{1,2}$, two new active agents, irinotecan and ox- aliplatin, have been introduced, and further incremental survival gains have been demonstrated for the combination of fluoropyrimidines with these drugs ${ }^{3,4}$, or, more recently, with targeted agents ${ }^{5,6}$. Raltitrexed, a drug that, like fluoropyrimidines, acts through thymidylate synthase inhibition has also been registered for the therapy of metastatic colorectal carcinoma ${ }^{7}$. However, the utilization of raltitrexed has been largely abandoned due to unpredictable toxicity. Currently, five classes of drugs with different mechanism of action are registered for the therapy of metastatic colorectal carcinoma, including fluoropyrimidines (5-fluorouracil and its pro-drug capecitabine) as antimetabolites, topoisomerase I inhibitor irinotecan, platinum derivative oxaliplatin, anti-vascular endothelial growth factor (VEGF) antibody bevacizumab and the monoclonal antibodies targeting epidermal growth factor receptor (EGFR) cetuximab and panitumumab. Unfortunately, these agents or their combinations are rarely curative in the setting of metastatic disease. In almost all patients initially responding to the therapy, the disease will eventually progress necessitating therapy with noncross resistant anticancer drugs. Even with the availability of more active agents, therapeutic options using agents 
currently registered or their combinations usually become exhausted during the course of the disease. Therefore, new active drugs, e.g. patupilone ${ }^{8}$, or more effective methods of administration of the active agents already identified, e.g. hepatic arterial infusion (HAI) need to be explored.

The liver represents the most common site of distant metastases in general. The liver is also the most common site of metastatic disease in colorectal carcinoma ${ }^{9-11}$. Moreover, the metastatic involvement of the liver is often isolated, i.e. without any extrahepatic metastases ${ }^{9}$. Distant metastases in colorectal cancer usually spread in a metastatic cascade, first affecting the liver, then spreading to the lungs, and only after lung involvement metastasizing to other organs ${ }^{9}$. This pattern of metastatic spread contrasts with other tumors, e.g. gastroesophageal or renal cell carcinomas ${ }^{12-15}$. Hepatic resection is currently the only curative therapy in patients with colorectal cancer liver metastases, but most patients with liver metastases present with non-resectable lesions, and these patients are treated by palliative chemotherapy. HAI of cytotoxic agents in patients with liver metastases has the advantage of higher intratumoral drug concentration and less systemic toxicity ${ }^{16}$. In patients with colorectal cancer metastatic to the liver, it has been demonstrated in clinical trials that these theoretical advantages translate into superior response rate and quality of life ${ }^{17,18}$. It has, however, been more difficult to demonstrate an improvement in survival, and only recently, a survival advantage of HAI compared to systemic chemotherapy could be demonstrat$\mathrm{ed}^{19}$. Consequently, the use of HAI in colorectal cancer metastatic to the liver is controversial. The role of HAI in patients with liver metastases of other primary tumors is even less clear.

\section{THEORETICAL FOUNDATIONS OF HAI}

Given the dose-response effect that is evident for many cytotoxic agents, there is an obvious attempt to administer the maximum tolerated dose. Cytotoxic drugs have some degree of selectivity for transformed neoplastic cells, but always have some toxic effects on normal tissues as well. Thus, increasing the dose results not only in higher efficacy, but also more side effects. Ultimately, systemic toxicity limits further dose escalation. Owing to limited inherent selectivity of cytotoxic drugs, different approaches have been explored to increase selectivity by other manipulations. One such approach is to exploit anatomy to achieve selective drug delivery. In some instances the tumor spread involves only certain anatomical compartments that may be targeted selectively. The aim is to increase the drug concentration in the tumor microenvironment with lower systemic concentrations that would result in limited toxicity. The strategy of anatomical targeting may be used in cases of superficial tumor spread inside the peritoneal cavity, urinary bladder and meningeal space. Similarly, vascular structures may be used to target the tumor, e.g. in cases of tumors of the extremities or liver tumors. In addition, intraarterial administration may take advantage of the first-pass effect.
The pharmacokinetic advantage of intraarterial compared to systemic administration of a drug may be quantified $^{20}$. The increase of target drug concentration by regional compared to systemic administration may be expressed by the ratio:

$\mathrm{R}_{\text {target }}=\mathrm{C}_{\text {target }}$ (regional administration) $/ \mathrm{C}_{\text {target }}$ (intravenous administration),

whereas decreased systemic concentration may be expressed in a similar manner to:

$\mathrm{R}_{\text {systemic }}=\mathrm{C}_{\text {systemic }}$ (regional administration) $/ \mathrm{C}_{\text {systemic }}$ (intravenous administration) ( ref. $\left.^{20}\right)$. C denotes here the steadystate drug concentration in case of continuous infusion or area under the curve in case of bolus administrations.

The selectivity of regional administration $\left(R_{d}\right)$ may be defined by the ratio:

$\mathrm{R}_{\mathrm{d}}=\mathrm{R}_{\text {target }} / \mathrm{R}_{\text {systemic }}$

This ratio may be estimated by the following formula:

$\mathrm{R}_{\mathrm{d}}=1+\mathrm{CL}_{\mathrm{TB}} / \mathrm{Q} \times(1-\mathrm{E})$,

where $\mathrm{CL}_{\mathrm{TB}}$ is the total body clearance, $\mathrm{Q}$ is the regional exchange rate and $\mathrm{E}$ is the fraction extracted during the first pass $^{20}$.

HAI, intraaterial infusion via the hepatic artery, is the method of regional chemotherapy most commonly used. Normal liver parenchyma has a blood supply from both the portal vein and hepatic artery. Seeding of liver metastases occurs hematogenously via portal blood supply. While small tumors have blood supply from both portal vein and hepatic artery ${ }^{21-23}$, with increasing tumor size the arterial supply prevails, and large tumors are supplied almost exclusively by the branches of the hepatic artery ${ }^{21-24}$. Sigurdson et al. ${ }^{25}$ compared hepatic and tumor floxuridine concentrations after HAI or portal vein infusion. While the drug concentrations were comparable in the liver, tumor floxuridine concentrations were more than an order of magnitude higher after HAI ( ref. $^{25}$ ).

Since many cytotoxic drugs are metabolized in the liver, HAI takes advantage of the first-pass effect. The pharmacokinetic advantage is best defined for fluoropyrimidines, 5-fluorouracil, 5-fluoro-2'-deoxyuridine (floxuridine), and 5'-deoxy-5-fluorouridine (doxifluridine). 5-fluorouracil and floxuridine were available since 1950 s $\left(\right.$ ref. $^{26}$ ). The synthesis of doxifluridine was first reported by Hřebabecký and Beránek in 1978 (ref. ${ }^{27}$ ), but this drug has mostly been used in Eastern Asia. The pharmacokinetics of HAI of 5-fluorouracil and floxuridine has been extensively studied ${ }^{28-31}$. The hepatic extraction ratio and clearance is significantly higher for floxuridine than for 5-fluorouracil ${ }^{29}$.

The effectiveness of HAI may be limited by the presence of arterial-venous shunts that may be detected by sorbitol clearance. It has been observed that the systemic toxicity of HAI is higher in patients with arterial-venous shunts ${ }^{32}$. Attempts have been made to harness therapeutically the absence of continuous smooth muscle layer and autonomic innervations in tumor blood vessels compared to normal $\operatorname{arteries}^{33}$, but the results of clinical studies have been disappointing ${ }^{34,35}$. It remains to be determined whether this difference between normal and tumor blood vessels could be exploited in combinations of HAI and targeted agents.

HAI results in higher drug concentrations and efficacy only in tumors supplied by the hepatic artery. Drug concen- 
trations and efficacy in extrahepatic tumors is usually lower when the drug is administered as HAI. Therefore, HAI is effective only in tumors limited to the liver.

\section{CLINICAL EXPERIENCE WITH HAI}

\section{Early studies with HAI}

Early studies with HAI were conducted using fluoropyrimidines, 5-fluorouracil or floxuridine. Early experience with HAI of 5-fluorouracil in different primary tumors was summarized by Ansfield et al. ${ }^{36}$. Of 428 patients included in the cohort, 381 had colorectal primary. The definition of response in this early study differed from the current definitions relying on imaging, and the response was defined as reduction of liver size, decrease in liver enzymes or, in case of hyperbilirubinemia, serum bilirubin. The response was not analyzed according the tumor type, but in the whole cohort the response defined by the criteria outlined above was observed in $55 \%$ of patients. It has been noted that in 36 jaundiced patients with colorectal primary the jaundice disappeared in 11 cases.

In 1980s and early 1990s several randomized trials comparing HAI of fluoropyrimidines with systemic administration of fluoropyrimidines or best supportive care $^{37-42}$. In these studies, usually HAI resulted in higher objective response rate. It has also been demonstrated that HAI results in superior quality of life compared with systemic chemotherapy ${ }^{18}$. However, the survival advantage was evident only in some of these trials that had also untreated patients in the control arm. All these studies were underpowered to detect a survival advantage. Moreover, the intent-to-treat analyses in these trials included substantial number of patients in the HAI arm who could not be treated because of technical problems, and sometimes a cross-over from the control to the HAI was allowed. Only one study failed to demonstrate higher response rate for HAI, probably because of methodological issues that prevented the administration of HAI in $37 \%$ of randomized patients and in another $29 \%$ of patients being administered less than 6 cycles of therapy ${ }^{43}$. A survival advantage was demonstrated in a more recent randomized trial comparing a systemic bolus regimen of 5-fluorouracil and leucovorin with the combination of HAI of floxuridine and dexamethasone ${ }^{19}$. In this trial, both objective response rate ( $47 \%$ vs. $24 \%$ ) and overall survival (median 24 vs. 20 months) was significantly better in the HAI arm. However, these results were published at a time when the systemic chemotherapy evolved several steps from the control arm in this study. Nevertheless, this trial constitutes proof of the principle of the superiority of HAI over systemic administration of cytotoxic agents. The results of these randomized trials were summarized in a few meta-analyses ${ }^{17,44,45}$. In the most recent meta-analysis, 10 randomized clinical trials that enrolled a total of 1277 patients were analyzed ${ }^{45}$. This meta-analysis confirmed significantly higher response rate for HAI (43\% vs. 18\%), but the difference in overall survival (median 16 vs. 12 months) was not statistically significant.
In most of the trials, floxuridine, the drug with better pharmacokinetic parameters of regional selectivity, was used for HAI. On the other hand, 5-fluorouracil is more commonly available and has been widely used in clinical practice. However, in one study comparing HAI of floxuridine, HAI of 5-fluorouracil/leucovorin and systemic administration of 5-fluorouracil/leucovorin the clinical efficacy in both HAI was comparable (response rate $43 \%$ and $45 \%$, respectively) (ref. ${ }^{46}$ ), suggesting that the pharmacokinetic advantage of floxuridine may not translate into superior clinical efficacy. Fluoropyrimidines used in the early studies of HAI, 5-fluorouracil and floxuridine, still constitute the backbone of most HAI regimens used for colorectal cancer liver metastases. With the advent of combination chemotherapy, HAI regimens administering fluoropyrimidine in monotherapy are no longer used as first-line treatment. However, as indicated by a recent report the HAI of floxuridine may represent an effective second or third line treatment option ${ }^{47}$. The most important randomized trials comparing HAI with systemic chemotherapy are summarized in Table 1.

\section{Efficacy of HAI utilizing agents other than fluoropyrimidines}

The current standard of systemic chemotherapy in patients with metastatic colorectal carcinoma is the administration of fluoropyrimidines with irinotecan, oxaliplatin or both agents, based on demonstration of improved outcome in randomized clinical trials $\mathrm{s}^{3,4,48,49}$. The improvement of survival associated with the advent of new cytotoxic agents was even noted in some retrospective cohorts of patients treated with HAI and, subsequently, with systemic chemotherapy ${ }^{50}$. As the combination chemotherapy replaced fluoropyrimidine monotherapy or administration of fluoropyrimidines potentiated by leucovorin as standard of care for the systemic treatment of metastatic colorectal carcinoma, the potential of HAI of oxaliplatin and irinotecan was also investigated. In most of these studies, oxaliplatin, irinotecan or other agents were combined with fluoropyrimidines. "Hybrid" chemotherapy regimens combining HAI of fluoropyrimidines and systemic administration of a second cytotoxic agent, or vice versa, were also studied.

Oxaliplatin and irinotecan became widely available in the late 1990s. In an earlier era, only drugs with marginal single-agent activity in metastatic colorectal carcinoma could be combined with HAI of fluoropyrimidines. While mitomycin $\mathrm{C}$ alone ${ }^{51}$, or in combination with 5-fluorouracil and anthracyclines ${ }^{52}$ has demonstrated activity when administered as HAI, other retrospective data indicate that addition of mitomycin $\mathrm{C}$ or anthracyclines to the combination of 5-fluorouracil and leucovorin has little effect on survival ${ }^{50}$. In another study Kemeny et al. ${ }^{53}$ randomized 95 patients to the HAI of floxuridine monotherapy or the HAI of the combination of mitomycin $\mathrm{C}$ and carmustine. The trend to higher response rate and longer overall survival did not reach statistical significance.

Encouraging activity has been reported for the HAI of oxaliplatin in a number of studies ${ }^{54-60}$. In a phase I study 


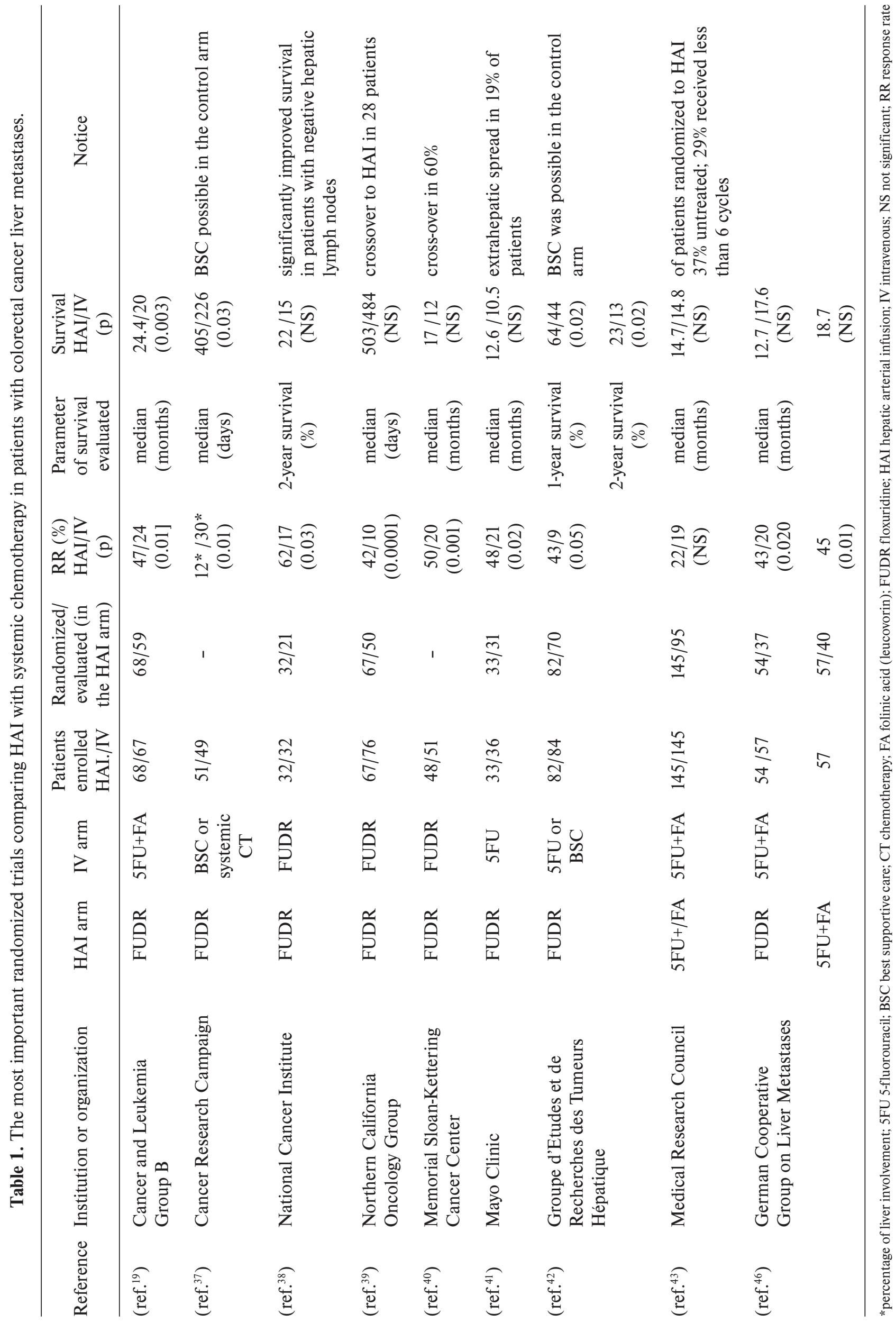


of oxaliplatin monotherapy administered as 30-minutes $\mathrm{HAI}$ in pre-treated patients, the dose limiting toxicity was reached at $175 \mathrm{mg} / \mathrm{m}^{2}$ (ref. $\left.{ }^{60}\right)$. The dose recommended for further study was $150 \mathrm{mg} / \mathrm{m}^{2}$, and using this dose, objective response rate of $33 \%$ and a disease control rate of $50 \%$ were obtained. Median survival was 13 months ${ }^{60}$. When administered as continuous 5-day HAI at a dose of $20 \mathrm{mg} / \mathrm{m}^{2} /$ day the objective response rate with oxaliplatin monotherapy was $46 \%$ and disease control rate was $67 \%$, with median survival being 19 months ${ }^{58}$. However, similarly to systemic chemotherapy most studies of HAI of oxaliplatin reported on the combinations with 5-fluorouracil and leucovorin. In a phase I study the recommended dose of oxaliplatin administered as HAI in combination with 5-fluorouracil and leucovorin was $125 \mathrm{mg} / \mathrm{m}^{2}$ every 3 weeks $^{54}$. A very promising response rate of $56 \%$ was reported in this phase I trial ${ }^{54}$. HAI of oxaliplatin was also administered in a bimonthly regimen at a dose of 100 $\mathrm{mg} / \mathrm{m}^{2}$ in combination with 5-fluorouracil and leucovorin administered as HAI (ref. ${ }^{55,56}$ ) or systemically ${ }^{57,59}$. When administered as second or higher line of therapy, the objective response rate and overall survival ranged between $24 \%$ to $55 \%$ and 16 to 18 months, respectively ${ }^{55-57}$. In a predominantly first-line population, the response rate of HAI of oxaliplatin combined with systemic administration of 5-fluorouracil and leucovorin was $64 \%$ and median survival was 27 months ${ }^{59}$. Abdominal pain has been reported as a peculiar side effect of HAI of oxaliplatin in a number of studies ${ }^{58-60}$. The results of HAI of the combination of oxaliplatin, 5-fluorouracil, leucovorin and mitomycin $\mathrm{C}$ have also been reported in a small pilot study with promising activity ${ }^{61}$. Systemic oxaliplatin was also combined with HAI of 5-fluorouracil resulting in a response rate of $41 \%$ (ref. $^{62}$ ). In a retrospective report, the experience with sequential administration of HAI of 5-fluorouracil followed by the systemic combination of oxaliplatin, 5-fluorouracil and leucovorin (FOLFOX) was described with response rates after HAI and FOLFOX of $85 \%$ and $35 \%$, respectively ${ }^{63}$.

A number of reports have also been published on HAI of irinotecan ${ }^{64-66}$. In a phase I trial maximum tolerated dose of irinotecan administered for 5 days every 3 weeks was $25 \mathrm{mg} / \mathrm{m}^{2}$ (ref. ${ }^{67}$ ). The conversion rate to $\mathrm{SN}$ 38 , the active metabolite of irinotecan, was higher with HAI when the pharmacokinetic data were compared with intravenous infusion in the same individual. The systemic concentrations of irinotecan were lower with HAI while systemic concentrations of SN-38 were similar for HAI and intravenous infusion ${ }^{67}$. The liver tissue is characterized by high activity of carboxylesterase that converts irinotecan to SN-38 (ref. ${ }^{68}$ ), and this enzymatic activity may be responsible for the higher conversion rate to $\mathrm{SN}$ 38 with HAI. From another phase I trial examining a different schedule, the recommended dose of irinotecan administered as HAI monotherapy emerged at $200 \mathrm{mg} / \mathrm{m}^{2}$ every 3 weeks ${ }^{64}$. The response rate in the phase I cohort was $14 \%$ while in the phase II cohort of previously treated patients the response rate was $33 \%$. In a pilot experience in 15 patients, objective response was observed in 5 and stable disease in 7 patients $^{65}$. In a phase II trial HAI of irinotecan, 5-fluorouracil and leucovorin was combined with oral administration of UFT (combination of tegafur and uracil in 1: 4 molar ratio) and leucovorin in 31 patients with metastatic colorectal carcinoma ${ }^{66}$. Partial response was observed in 20 (65\%) patients, and median survival was 36 months. Irinotecan can also be administered using sulfonate hydrogel microsphere, drug-eluting bead, irinotecan (DEBIRI). In a study that enrolled 55 heavily pretreated metastatic colorectal carcinoma patients objective response was observed in $36(65 \%)$ patients, median progression-free survival was 11 months and median survival was 19 months $^{69}$. In a phase I/II study, systemic administration of irinotecan was combined with HAI of 5-fluorouracil and oral UFT ( ref. $^{70}$ ). The recommended dose of irinotecan from the phase I part of the trial was $140 \mathrm{mg} / \mathrm{m}^{2}$. Of 22 patients enrolled in the phase II part of the study, 19 patients $(86 \%)$ had partial response and 14 patients subsequently underwent liver resection ${ }^{70}$. Systemic administration of irinotecan was also studied in combination with HAI of floxuridine in 39 heavily pretreated patients resulting in $44 \%$ response rate with median survival of 20 months $^{71}$.

HAI of the combination of oxaliplatin, irinotecan and 5-fluorouracil administered in a chronomodulated regimen was studied in 29 heavily pretreated metastatic colorectal carcinoma patients ${ }^{72}$. Partial response was observed in 10 patients (35\%) and resection could be performed in 4 patients. Median progression-free survival and overall survival were 5 months and 18 months, respectively $^{72}$. Chen et al. reported on HAI of oxaliplatin, irinotecan and doxifluridine in combination with systemic administration of doxifluridine and leucovorin in 32 patients $^{73}$. Objective response was noted in $61 \%$ of patients treated in the first line and $29 \%$ of pretreated patients.

The number of cytotoxic agents active in metastatic colorectal carcinoma is limited. Thus, it is not surprising that few studies are available on the activity of agents other than fluoropyrimidines, oxaliplatin or irinotecan administered as HAI. In fact, most other agents were combined with one of the drugs with established activity in metastatic colorectal carcinoma. In a pilot study, HAI of the combination of oxaliplatin and raltitrexed was studied in 17 patients pretreated by both oxaliplatin and irinote$\mathrm{can}^{74}$. Three complete responses and 8 partial responses were observed for an overall response rate of $65 \%$. The median survival of 28 months in this heavily pretreated cohort is encouraging, but, similar to the experience with systemic administration of raltitrexed, serious toxicity was found, and one patient with grade 4 neutropenia died of septic shock. HAI of high-dose melphalan (200 mg) was studied in 30 , mostly pre-treated patients administered HAI regimen using isolated hepatic perfusion ${ }^{75}$. Partial response was observed in 15 patients, but the treatment was complicated by significant hepatic toxicity, including one death from liver failure. In a phase II trial, HAI of pirarubicin in combination with systemic 5-fluorouracil and leucovorin resulted in a response rate of $32 \%\left(\right.$ ref. $\left.^{76}\right)$. Objective response was also reported in 4 out of 17 (24\%) 
of patients treated with HAI of fotemustine ${ }^{77}$. Anecdotally, a long-term complete response has been reported after HAI of the combination of oxaliplatin and gemcitabine ${ }^{78}$.

\section{HAI combined with targeted therapy}

The advent of targeted therapy has had major impact on the management of metastatic colorectal carcino$\mathrm{ma}^{5,79,80}$. It has been demonstrated in prospective randomized trials that the administration of targeted agents results in improved outcomes, including significant prolongation of overall survival, in both chemotherapy-naïve and pre-treated patients with metastatic colorectal cancer. Currently, three targeted agents are registered for the therapy, antibody against VEGF bevacizumab ${ }^{81}$ and antibodies against EGFR cetuximab ${ }^{6,82}$ and panitumumab ${ }^{80}$. Most promising results were found when these monoclonal antibodies were combined with cytotoxic agents ${ }^{5,81,82}$.

So far, only a limited number of reports of pilot studies that investigated combinations of HAI of cytotoxic agents with anti-VEGF or anti-EGFR monoclonal antibodies have been published ${ }^{83-86}$. Neyns et al.$^{83}$ reported pilot experience with systemic administration of cetuximab combined either with HAI of oxaliplatin or systemic irinotecan and HAI of 5-fluorouracil and leucovorin in 8 patients with liver metastases of colorectal carcinoma. Partial response was observed in 5 patients. An unusual side effect of cystic bile duct dilatation was noted in 2 patients. The combination of HAI of oxaliplatin with systemic administration of 5-fluorouracil, leucovorin and bevacizumab was studied in 6 patients with malignancies refractory to standard treatment (including 3 patients with colorectal carcinoma liver metastases) (ref. $\left.{ }^{84}\right)$. Among patients responding to this therapy was one patient with colorectal primary. The combination of HAI of oxaliplatin with systemic administration of 5-fluorouracil, leucovorin and bevacizumab was further investigated in a phase I trial in 57 heavily pretreated primary and secondary liver tumors $^{86}$. The maximum tolerated dose of oxaliplatin was $140 \mathrm{mg} / \mathrm{m}^{2}$. Among 28 patients with colorectal primary, 3 patients $(11 \%)$ had partial response and 11 patients $(32 \%)$ had stable disease for more than 4 months. The effect of addition of bevacizumab to HAI of floxuridine was also investigated in a phase II randomized trial in patients after liver resection ${ }^{85}$, but no apparent benefit of the combined therapy was evident.

Theoretically, the combination of HAI of oxaliplatin with bevacizumab may be of advantage because of the protective effect of bevacizumab on oxaliplatin-induced liver injury ${ }^{87}$. On the other hand, the biliary toxicity of floxuridine in combination with bevacizumab was increased ${ }^{85}$. The efficacy of HAI in combination with cetuximab or bevacizumab seem to be promising, especially in heavily pretreated patients. The combinations of HAI with targeted agents should be explored in further prospective trials.

\section{Advantages and pitfalls of HAI}

In selected patients, HAI is a highly effective therapeutic method. However, a number of factors limit the effectiveness or use of this treatment approach, includ- ing catheter or port system-related complications, the presence of extrahepatic metastases, and increased risk of hepatic toxicity. As summarized above, HAI has the advantage of higher efficacy and, importantly, lower systemic toxicity. Decreased systemic exposure may be viewed as an advantage as well as a drawback since it is associated with decreased toxicity, but also with suboptimal systemic exposure with less activity on extrahepatic disease ${ }^{88}$. These advantages and disadvantages should be weighted when deciding about indication for HAI.

For HAI, an intraarterial catheter needs to be introduced into the hepatic artery. Technical problems with the catheter, port system or implanted pump are common and frequently result in the delay or discontinuation of therapy ${ }^{62,89}$. These technical problems also manifested in clinical trials, and, in some studies, a substantial proportion of patients randomized to HAI could not be treated ${ }^{43}$. Historically, the placement of the intraarterial catheter with subcutaneous chamber of the port system or pump was performed surgically, but currently intraarterial catheters with the port system are commonly introduced by interventional radiologists ${ }^{90,91}$. Retrospective analysis comparing the surgical versus interventional route of implantation suggest that the rate of complications tend to be higher and the duration of port system function is significantly shorter when the surgical approach is used ${ }^{91}$. In fact, in many centers, implantation of the catheter by interventional radiology is currently preferred over the surgical approach ${ }^{89}$.

An important cause of failure of HAI is the manifestation of extrahepatic metastases. When cytotoxic agents are administered solely using HAI, the systemic drug concentrations are lower, resulting in the emergence of extrahepatic metastases that could be potentially resistant to cytotoxic agents that were administered via HAI. To counter this problem, HAI has been combined with systemic administration of anticancer agents. An issue of obvious importance is the selection of patients with isolated hepatic metastases (liver-only disease) for HAI.

Theoretically, it could be thought that the hepatotoxicity of cytotoxic agents administered by HAI might present a serious problem, but in clinical practice the liver toxicity of agents administered in HAI regimens is, with few exceptions, limited. Hepatic toxicity of chemotherapy, whether administered as HAI or systemically, is a significant issue in patients with hepatocellular carcinoma because of the presence of liver cirrhosis in the majority of patients, but cirrhosis is rare in the population of patients with colorectal carcinoma liver metastases and, consequently, the incidence of serious hepatic toxicity is low. Although from the pharmacokinetic perspective HAI of floxuridine has the biggest advantage, the HAI of this agent is associated with significant biliary toxicity, and floxuridine has to be administered with dexamethasone. HAI of floxuridine with or without dexamethasone was studied in a small randomized trial ${ }^{53}$. The addition of dexamethasone not only resulted in less biliary toxicity, but also in a higher response rate (71\% vs. $40 \%$ ). Dexamethasone itself may have some antitumor activity, possibly mediated through 
inhibition of angiogenesis ${ }^{92}$. Oxaliplatin, whether administered as HAI or systemically, also induces a peculiar form of liver toxicity manifesting as sinusoid obstruction syndrome ${ }^{93,94}$. Liver toxicities associated with the administration of agents commonly used in colorectal carcinoma include non-alcoholic fatty liver disease after 5-fluorouracil and steatohepatitis after irinotecan ${ }^{95}$. These toxicities may complicate liver surgery when neoadjuvant strategy is employed ${ }^{95}$, but it is currently not known whether these toxic side effects are more prominent with HAI. So far, no warning safety signals regarding hepatic toxicity have been reported from trials using HAI of oxaliplatin or irinotecan.

The problems associated with the use of HAI had an obvious effect on clinical trials that studied this approach. In general, these studies have some common problems, including low statistical power due to the need to select patients with isolated liver metastases and inability to administer HAI in a significant proportion of the intentionto-treat population due to catheter-related problems. On the other hand, lower systemic toxicity is the major advantage of HAI in this patient population. Systemic administration of anticancer therapy in patients with metastatic colorectal carcinoma is frequently accompanied by side effects, with hematological and gastrointestinal toxicities ${ }^{96}$ being the most frequent complications. A more favorable safety profile of HAI has been apparent across the clinical trials. Importantly, it has been demonstrated that lower toxicity translates into superior quality of life in patients treated with HAI (ref. ${ }^{18}$ ). Also toxicities associated with targeted treatments, e.g. skin toxicity associated with the anti-EGFR therapy ${ }^{97}$, have major impact on the quality of life.

The identification of clinical and laboratory parameters that could predict response is of major importance in medical oncology. This issue is even more important for an invasive approach like HAI. An obvious clinical predictive factor is the absence of extrahepatic metastases. Recently, much attention in the management of colorectal carcinoma has been focused on laboratory predictive and prognostic factors, i.e. biomarkers. Only limited information is available on the biomarkers that could predict the response to HAI (ref. ${ }^{19}$ ). In one trial, the combination of the tumor expression of thymidylate synthase and p53 was predicting overall survival ${ }^{19}$. In clinical practice, the same biomarkers are utilized in patients treated with HAI as in the metastatic colorectal cancer patients in general. In patients with primary and secondary liver tumors, including patients with liver metastases of colorectal carcinoma an immune deficit that manifests as low number of $\mathrm{CD}^{+}$ T-cells is frequently present ${ }^{98}$. An inverse correlation has been described between peripheral blood CD4 $4^{+}$T-cells and urinary concentrations of neopterin, a biomarker of systemic immune response ${ }^{98}$. High neopterin concentrations are an independent predictor of poor prognosis in patients with metastatic colorectal carcinoma ${ }^{99}$.

\section{HAI and other liver-directed procedures}

As mentioned above, the liver is the most common site of distant metastases. Different liver-directed therapies have been proposed for the treatment of primary or secondary (metastatic) liver tumors. Liver-directed therapies may be distinguished into direct methods that include resection, intratumoral injection or radiofrequency ablation (RFA) and vascular methods that include HAI. With regard to liver-directed therapies, tumors metastasizing to the liver may be distinguished into 3 categories based on how frequently are liver-directed treatments appropriate in individual patients; often appropriate, occasionally appropriate or seldom appropriate ${ }^{100}$. Because of the biology and pattern of metastatic spread, colorectal carcinoma is an example of tumor that is often appropriate for liverdirected therapies. In fact, given the high incidence of this tumor, colorectal carcinoma is in many countries the most common indication for liver-directed therapies, including liver resection or HAI.

Although, with few exceptions, metastatic solid tumors are regarded as incurable disease, a small proportion of patients with colorectal carcinoma liver metastases can be cured with liver resection. Resection is feasible only in a minority of patients, and long-term cure is achieved in only $30-40 \%$ of patients who undergo the procedure ${ }^{101}$. However, there is cumulative evidence that multimodality approach that includes both liver resection and chemotherapy may result in more patients being able to undergo resection as well as in improved long-term survival after resection. Because of high efficacy of $\mathrm{HAI}$ in patients with isolated liver metastases, the potential of this approach in neoadjuvant and adjuvant setting has been studied.

As outlined above, patients with isolated liver metastases in whom primary liver resection can be performed represent only a minor proportion of the population of patients with metastatic colorectal cancer. Thus, prospective trials of adjuvant therapy in patients undergoing liver resection were difficult in terms of recruiting sufficient patients to answer the questions regarding the efficacy of this treatment. It is therefore not surprising that definitive evidence for the role of adjuvant chemotherapy, systemic or HAI, in patients after liver resection is still lacking. Kemeny et al. randomized 156 patients after liver resection to systemic 5-fluorouracil/leucovorin or the same systemic therapy combined with HAI of floxuridine and demonstrated prolongation of survival in the combined therapy arm (median 72 vs. 59 months) (ref. ${ }^{102}$ ). In a subsequent trial, Kemeny et al. compared the observation (no treatment) with the combination of HAI of floxuridine and continuous infusion of 5-fluorouracil ${ }^{103}$. Significantly more patients were free of liver recurrence (46\% vs. $25 \%$ ) or any recurrence ( $67 \%$ vs. $43 \%$ ) in the combined therapy arm, but because of limited sample size, prolongation of survival could not be demonstrated. In another trial comparing HAI of 5-fluorouracil and leucovorin versus observation in patients after liver resection there was no evidence of improved survival with the use of HAI, but, like many trials in patients with unresectable metastases, a significant proportion of patients randomized to HAI were never treated ${ }^{104}$. Adjuvant administration of HAI after liver resection has also been explored in combination with systemic administration of other drugs or in regimen alternating HAI with systemic chemotherapy. In a pilot 
study Kemeny et al. combined HAI of floxuridine and dexamethasone with systemic administration of irinotecan $^{105}$. The maximum tolerated dose of irinotecan was 200 $\mathrm{mg} / \mathrm{m}^{2}$. Two-year survival was $89 \%$, but extrahepatic recurrence was evident in most patients. A trend of improved outcome was noted in patients treated with maximum tolerated dose. In a phase II trial, HAI of floxuridine and dexamethasone was alternated with systemic administration of oxaliplatin and capecitabine ${ }^{106}$. The 2-year survival rate was $88 \%$, and median disease-free survival was 33 months. Although these results of combined HAI and systemic multidrug therapy are promising, they remain to be confirmed in prospective randomized trials. The results of randomized trials studying adjuvant systemic chemotherapy or HAI after liver resection were also studied in meta-analyses ${ }^{107,108}$. In a meta-analysis focusing on HAI, the trend of improved survival did not reach statistical significance ${ }^{107}$. In a more recent meta-analysis studying both systemic chemotherapy and HAI both methods improved recurrence-free survival, but there was no significant survival difference ${ }^{108}$.

Neoadjuvant chemotherapy represents another approach aimed at increasing the cure rate of patients with colorectal cancer liver metastases. Different regimens of systemic chemotherapy or HAI have been evaluated in the neoadjuvant setting in this patient population ${ }^{109}$. The assessment of the potential of neoadjuvant approach in improvement of long-term results of liver resection was even more difficult than in the adjuvant setting. For obvious reason, the treating physicians were reluctant to enroll patients with clearly resectable lesions into trials of therapies that could potentially fail, resulting in non-resectability in a case deemed originally resectable. The studies of neoadjuvant chemotherapy in colorectal cancer liver metastases have therefore focused more or less on selected patients with metastases that were originally judged unresectable, or the resectability was considered questionable. Most studies on the effect of HAI on resectability and longterm survival are retrospective series. In one of the earlier studies, promising neoadjuvant activity has been reported by Link et al. for a combined HAI regimen ${ }^{52}$. Goéré et al. reported on a series of 87 , mostly pre-treated patients treated with the combination of HAI of oxaliplatin with systemic 5-fluorouracil and leucovorin ${ }^{89}$. In this series, resection or RFA was performed in 21 patients, and 5-year survival after surgery was $56 \%$. The resection rate was higher in patients who received HAI in the first line. In another analysis of 49 patients treated with HAI of floxuridine with systemic oxaliplatin and irinotecan, objective response was observed in 45 patients (92\%) and the resection was performed in 23 patients (47\%) (ref. ${ }^{110}$ ). Again, the response and resection rates were higher in patients treated in the first line. Liver resections were also reported after HAI administered as second or third line of therapy of colorectal carcinoma liver metastases ${ }^{47,57,71,72}$. HAI has also been successfully combined with RFA (ref. ${ }^{89,111}$ ). In a prospective study, HAI of floxuridine was combined with RFA or RFA plus resection in 21 patients with up to 10 lesions $^{111}$. The median liver-specific disease-free survival and overall survival were 17 and 30 months, respectively.

\section{Adjuvant regional chemotherapy in patients without manifest liver metastases}

Adjuvant therapy may be defined as the treatment of distant metastases that are not detectable by conventional imaging studies, but are presumed to be present based on expected recurrence rates. Given the high rate of metachronous liver metastases in patients with colorectal cancer, it is not surprising that regional approaches have been also investigated in the adjuvant setting in patients with stage II or III colorectal carcinoma. As outlined above, small subclinical metastases, unlike overt metastases diagnosed with routine imaging, are supplied by both hepatic artery and portal vein system. Thus both HAI and portal vein infusion (PVI) have been studied in the adjuvant setting in a number of studies.

HAI has also been combined with other regional approaches. $\mathrm{Xu}$ et al. reported a trial that randomized 222 patients with stage II and III colorectal carcinoma to preoperative oxaliplatin and floxuridine administered as HAI and into the artery supplying the primary tumor ${ }^{112}$. The preoperative regional chemotherapy resulted in significant reduction of the risk of liver metastasis, any recurrence and death in patients with stage III disease, while the trend of improved outcome in patients with stage II tumors did not reach statistical significance. The results of randomized trials of HAI or PVI have recently been summarized in a recent meta-analysis ${ }^{113}$. This meta-analysis included 2 trials of HAI and 7 trials of PVI. Perioperative administration of HAI was associated with significant improvement of 5-year mortality rate (13\% vs. $27 \%$; HR $0.46 ; P=0.0002$ ) over surgery alone, but the no effect on mortality rate was evident for PVI. Administration of HAI also resulted in significantly lower rate of liver metastases ( $11 \%$ vs. $25 \% ; P=0.0002$ ) ( ref. $^{113}$ ).

\section{Current role of $\mathrm{HAI}$ in the management of patients with colorectal cancer liver metastases}

HAI may be regarded as an investigational method that has been studied extensively in clinical trials. Despite studies that have been performed with HAI over the last five decades, the role of HAI in the management of patients with hepatic metastases of colorectal cancer remains controversial. Recently, Kemeny defined 3 circumstances under which HAI could be considered in clinical practice, including HAI as adjuvant treatment in patients after liver resection, HAI as a second or higher line of therapy in patients failing standard front line regimens, or HAI as neodjuvant therapy to convert to resectability ${ }^{114}$. All these indications are supported by extensive data, although all studies supporting this use suffered from similar problems to other trials of HAI. "Hybrid" chemotherapy regimens that combine HAI and systemic administration of cytotoxic agents could be of advantage in this setting because of the potential to control hepatic as well as extrahepatic disease, but this has so far not been proven in randomized clinical trials. One distinct advantage of HAI in the neoadjuvant or adjuvant therapy in association with liver resection is less limitation regarding the timing of the treatment before and after surgery. Bevacizumab, the targeted agents most commonly administered in combination with che- 
motherapy in the first-line setting, impairs wound healing and an interval of at least 28 days is recommended between the administration of bevacizumab and surgery. Moreover, administration of bevacizumab is considered risky or even contraindicated in patients with some comorbidities, e.g. thrombembolic disease or inflammatory bowel disease, and HAI of combined chemotherapy may provide an effective alternative to the systemic administration of bevacizumab with combination chemotherapy.

The efficacy of HAI administered as second or higher line of therapy varies significantly. Relatively low efficacy has been reported in studies using fluoropyrimidine monotherapy ${ }^{115}$, but high response rate and prolonged survival have been reported in patients treated with combined regimens ${ }^{55-57,72}$. Obviously, the patient selection plays a significant role in the second or higher line therapy setting, and prolonged survival has been documented in individual patients, even when using HAI of drugs administered earlier in the course of therapy ${ }^{72}$.

Even at the time when HAI offered the highest disease control rates of all available therapies, the utilization of this approach differed markedly among institutions. With the introduction of targeted therapies, the use of HAI has decreased even in centers that have been the most ardent advocates of this method. However, there are certainly patients who may benefit from this approach, and HAI should remain an option in the therapeutic armamentarium for patients with isolated liver metastases of colorectal carcinoma.

\section{CONCLUSIONS}

In spite of all its limitations, HAI remains a promising approach in the therapy of colorectal cancer patients with isolated liver metastases. The data on HAI of fluoropyrimidines are currently more or less only of historical interest, since the standard of care has changed. Promising activity was observed with HAI of combination chemotherapy. The concurrent systemic administration of cytotoxic agents could limit extrahepatic disease as the cause of failure. Combined regimens comprising HAI of cytotoxic drugs and systemic administration of cytotoxic agents have demonstrated promising results and should be further investigated. Moreover, there is cumulative body of evidence that the combined HAI regimens increase resection rates and as part of multidisciplinary treatment approach may cure selected patients. Current standards of care for metastatic colorectal carcinoma comprise the combination of monoclonal antibodies targeting VEGF or EGFR in combination with chemotherapy, but, currently, only limited data are available on the combination of HAI with targeted agents. Future studies should specifically concentrate on identifying a regimen that would result in increased cure rates in patients with isolated hepatic metastases. Thus, exploiting anatomical selectivity may still be a useful approach even in the era of targeted agents.

\section{ACKNOWLEDGEMENT}

Supported by the IGA MZ grant NS/9690-4/2008.

\section{CONFLICT OF INTEREST STATEMENT}

Author's conflict of interest diclosure: The author stated that there are no conflicts of interest regarding the publication of this article.

\section{REFERENCES}

1. Scheithauer W, Rosen H, Kornek GV, Sebesta C, Depisch D. Randomised comparison of combination chemotherapy plus supportive care with supportive care alone in patients with metastatic colorectal cancer. Br Med J 1993;306:752-5.

2. Nordic Gastrointestinal Tumor Adjuvant Therapy Group. Expectancy or primary chemotherapy in patients with advanced colorectal cancer: a randomized trial. J Clin Oncol 1992;10:904-11.

3. Douillard JY, Cunningham D, Roth AD, Navarro M, James RD, Karasek P, Jandik P, Iveson T, Carmichael J, Alakl M, Gruia G, Awad L, Rougier P. Irinotecan combined with fluorouracil compared with fluorouracil alone as first-line treatment for metastatic colorectal cancer: a multicentre randomised trial. Lancet 2000;355:1041-7.

4. Tournigand C, Andre T, Achille E, Lledo G, Flesch M, Mery-Mignard D, Quinaux E, Couteau C, Buyse M, Ganem G, Landi B, Colin P, Louvet C, de Gramont A. FOLFIRI followed by FOLFOX6 or the reverse sequence in advanced colorectal cancer: a randomized GERCOR study. J Clin Oncol 2004;22:229-37.

5. Hurwitz $\mathrm{H}$, Febrenbacher $\mathrm{L}$, Novotny W, Cartwright $\mathrm{T}$, Hainsworth J, Heim W, Berlin J, Baron A, Griffing S, E. H, Ferrara N, Fyfe G, Rogers $B$, Ross R, Kabbinavar F. Bevacizumab plus irinotecan, fluorouracil, and leucovorin for metastatic colorectal cancer. N Engl J Med 2004;350:2335-42.

6. Jonker DJ, O Callaghan CJ, Karapetis C, Zalcberg JR, Tu D, Au HJ, Berry SR, Krahn M, Price T, Simes RJ, Tebbutt NC, van Hazel G, Wierzbicki $\mathrm{R}$, Langer C, Moore MJ. Cetuximab for the treatment of colorectal cancer. N Engl J Med 2007;357:2040-8.

7. Cunningham D, Zalcberg J, Maroun J, James R, Clarke S, Maughan TS, Vincent M, Schulz J, Gonzales Baron M, Facchini T. Efficacy, tolerability and management of raltitrexed (Tomudex) monotherapy in patients with advanced colorectal cancer: a review of phase II/III trials. Eur J Cancer 2002;38:478-86.

8. Melichar B, Casado E, Bridgewater J, Bennouna J, Campone M, Vitek P, Delord JP, Cerman J, Salazar R, Dvorak J, Sguotti C, Urban P, Viraswami-Appanna K, Tan E, Tabernero J. Clinical activity of patupilone in patients with pretreated advanced/metastatic colon cancer: results of a phase I dose escalation trial. Br J Cancer 2011;105:164653.

9. Weiss L, Grundmann E, Torhorst J, Harvett F, Moberg I, Eder M, Fenoglio-Preiser CM, Napier J, Horne CHW, Lopez MJ, Shaw-Dunn RI, Sugar J, Davies JD, Day DW, Harlos JP. Haematogenous metastastic patterns in colonic carcinoma: an analysis of 1541 necropsies. J Pathol 1986;150:195-203.

10. Lee CYTM. Carcinoma of the colon and rectum: Distribution of metastatic sites, risk factors and autopsy studies. GI Cancer 1998;2:255-66.

11. Patanaphan V, Salazar OM. Colorectal cancer: Metastatic patterns and prognosis. Southern Med J 1993;86:38-41.

12. Mafune Kl, Tanaka Y, Takubo K. Autopsy findings in patients with esophageal carcinoma: comparison between resection and nonresection groups. J Surg Oncol 2000;74:196-200.

13. Mandard AM, Chasle J, Marnay J, Villedieu B, Bianco C, Roussel A, Elie $\mathrm{H}$, Vernhes JC. Autopsy findings in 111 cases of esophageal cancer. Cancer 1981;48:329-35.

14. Quint LE, Hepburn LM, Francis IR, Whyte RI, Orringer MB. Incidence and distribution of distant metastases from newly diagnosed esophageal carcinoma. Cancer 1995;76:1120-5.

15. Weiss L, Harlos JP, Torhorst J, Gunthard B, Hartveit F, Svendsen E, Huang WL, Grundmann E, Eder M, Zwicknagl M, Cochrane HR, Stock 
D, Wright C, Horne CHW. Metastatic patterns of renal carcinoma: an analysis of 687 necropsies. J Cancer Res Clin Oncol 1988;114:605-12.

16. Venook AP, Warren RS. Regional chemotherapy approaches for primary and metastatic liver tumors. Surg Oncol Clin N Amer 1996;5:411-27.

17. Meta-Analysis Group in Cancer. Reappraisal of hepatic arterial infusion in the treatment of nonresectable liver metastases from colorectal cancer. J Natl Cancer Inst 1996;88:252-8.

18. Earlam S, Glover C, Davies M, Fordy C, Allen-Mersh TG. Effect of regional and systemic fluorinated pyrimidine chemotherapy on quality of life in colorectal liver metastasis patients. J Clin Oncol 1997;15:2022-9.

19. Kemeny NE, Niedzwiecki D, Hollis DR, Lenz HJ, Warren RS, Naughton MJ, Weeks JC, Sigurdson ER, Herndon II JE, Zhang C, Mayer RJ. Hepatic arterial infusion versus systemic therapy for hepatic metastases from colorectal cancer: a randomized trial of efficacy, quality of life, and molecular markers (CALGB 9481). J Clin Oncol 2006;24:1395 403.

20. Collins JM. Pharmacologic rationale for regional drug delivery. J Clin Oncol 1984;2:498-504.

21. Lin G, Lunderquist A, Hagerstrand I, Boijsen E. Postmortem examination of the blood supply and vascular pattern of small liver metastases in man. Surgery 1984;96:517-26.

22. Lien WM, Ackerman NB. The blood supply of experimental liver metastases. II. A microcirculatory study of the normal and tumor vessels of the liver with the use of perfused silicone rubber. Surgery 1970;68:334-40.

23. Ackerman NB. The blood supply of experimental liver metastases. IV. Changes in vascularity with increasing tumor growth. Surgery 1974;75:589-96.

24. Breedis C, Young G. The blood supply of neoplasms in the liver. Am J Pathol 1954;30:969-85.

25. Sigurdson ER, Ridge JA, Kemeny N, Daly JM. Tumor and liver drug uptake following hepatic artery and portal vein infusion. J Clin Oncol 1987;5:1836-40.

26. Ansfield FJ. Chemotherapy of disseminated solid tumors. J Natl Med Assoc 1962;54:658-61.

27. Hřebabecký H, Beránek J. 5-halogeno-2, 3-cyclic sulphite isomers in the preparation of 5-halogeno nucleosides. Synthesis of 5-deoxyuridine and 5-deoxy-5-fluorouridine. Nucleic Acids Res 1978;5:1029-39.

28. Goldberg JA, Kerr DJ, Watson DG, Willmott N, Bates CD, McKillop JH, McArdle CS. The pharmacokinetics of 5-fluorouracil administered by arterial infusion in advanced colorectal hepatic metastases. $\mathrm{Br} J$ Cancer 1990;61:913-5.

29. Ensminger WD, Rosowsky A, Raso V, Levin DC, Glode M, ome S, Steele G, Frei E. A clinical-pharmacological evaluation of hepatic arterial infusion of 5-fluoro-2-deoxyuridine and 5-fluorouracil. Cancer Res 1978;38:3784-92.

30. Armstrong RD, Diasio RB. Metabolism and biological activity of 5-deoxy-5-fluorouridine, a novel fluoropyrimidine. Cancer Res 1980;40:3333-8.

31. Schreiber R, Raso V. Radioimmunoassay for the detection and quantitation of 5-fluorodeoxyuridine. Cancer Res 1978;38:1889-92.

32. Bar F, Battista S, Bucchi MC, Zanon C, Grosso M, Alabiso O, Miraglia S, Cappello N, Gariboldi A, Molino G. Sorbitol removal by the metastatic liver: a predictor of systemic toxicity of intra-arterial chemotherapy in patients with liver metastases. J Hepatol 1999;30:1112-8.

33. Ashraf S, Crowe R, Loizidou MC, Turmaine M, Taylor I, Burnstock G. The absence of autonomic perivascular nerves in human colorectal liver metastases. Br J Cancer 1996;73:349-59.

34. Shankar A, Loizidou M, Burnstock G, Taylor I. Noradrenalin improves the tumour to normal blood flow ratio and drug delivery in a model of liver metastases. Br J Surg 1999;86:453-7.

35. Dworkin MJ, Zweit J, Carnochan P, Deehan B, Allen-Mersh TG. Effect of regional angiotensin II infusion on the relationship between tumour blood flow and fluorouracil uptake in a liver metastasis animal model. Eur J Cancer 1996;32A:1580-4.

36. Ansfield FJ, Ramirez G, Davis HL, Wirtanen GW, Johnson RO, Bryan GT, Manalo FB, Borden EC, Davis TE, Esmaili M. Further clinical studies with intrahepatic arterial infusion with 5-fluorouracil. Cancer 1975:36:2413-7.

37. Allen-Mersh TG, Earlam S, Fordy C, Abrams K, Houghton J. Quality of life and survival with continuous hepatic-artery floxuridine infusion for colorectal liver metastases. Lancet 1994;344:1255-60.
38. Chang AE, Schneider PD, Sugarbaker PH, Simpson C, Culnane M, Steinberg SM. A prospective randomized trial of regional versus systemic continuous 5-fluorodeoxyuridine chemotherapy in the treatment of colorectal liver metastases. Ann Surg 1987;206:685-93.

39. Hohn DC, Stagg RJ, Friedman MA, Hannigan JF, Rayner A, Ignoffo $\mathrm{RJ}$, Acord P, Lewis BJ. A randomized trial of continuous intravenous versus hepatic intraarterial floxuridine in patients with colorectal cancer metastatic to the liver: The Northern California Oncology Group trial. J Clin Oncol 1989;7:1646-54.

40. Kemeny N, Daly J, Reichman B, Geller N, Botet J, Oderman P. Intrahepatic or systemic infusion of fluorodeoxyuridine in patients with liver metastases from colorectal carcinoma. Ann Intern Med 1987; 107:459-65.

41. Kirk Martin J, O Connell MJ, Wieand HS, Fitzgibbons RJ, Mailliard JA Rubin J, Nagorney DM, Tschetter LK, Krook JE. Intra-arterial floxuridine vs systemic fluorouracil for hepatic metastases from colorectal cancer. Arch Surg 1990;125:1022-7.

42. Rougier $\mathrm{P}$, Laplanche $\mathrm{A}$, Huguier M, Hay JM, Ollivier JM, Escat J, Salmon R, Julien M, Roullet Audy JC, Gallot D, Gouzi JL, Pailler JL, Elisa D, Lacaine F, Roos S, Rotman N, Luboinski M, Lasser P. Hepatic arterial infusion of floxuridine in patients with liver metastases from colorectal carcinoma: Long-term results of a prospective randomized trial. J Clin Oncol 1992;10:1112-8.

43. Kerr DJ, McArdle CS, Ledermann J, Taylor I, Sherlock DJ, Schlag PM, Buckels J, Mayer D, Cain D, Stephens RJ. Intrahepatic arterial versus intravenous fluorouracil and folinic acid for colorectal cancer liver metastases: a multicenter randomised trial. Lancet 2003;361:368-73.

44. Harmantas A, Rotstein LE, Langer B. Regional versus systemic chemotherapy in the treatment of colorectal carcinoma metastatic to the liver. Is there a survival difference? Meta-analysis of the published literature. Cancer 1996;78:1639-45.

45. Mocellin S, Pilati P, Lise M, Nitti D. Meta-analysis of hepatic arterial infusion for unresectable liver metastases from colorectal cancer: The end of an era? J Clin Oncol 2007;25:5649-54.

46. Lorenz M, Muller HH. Randomized, multicenter trial of fluorouracil plus leucovorin administered either via hepatic arterial or intravenous infusion versus flurodeoxyuridine administered via hepatic arterial infusion in patients with nonresectable liver metastases from colorectal carcinoma. J Clin Oncol 2000;18:243-54.

47. Samaras P, Breitenstein S, Haile SR, Stenner-Liewen F, Heinrich $S$, Feilchenfeldt J, Renner C, Knuth A, Pestalozzi BC, Clavien PA. Selective intra-arterial chemotherapy with floxuridine as secondor third-line approach in patients with unresectable colorectal liver metastases. Ann Surg Oncol 2011;18:1924-31.

48. Saltz LB, Cox JV, Blanke C, Rosen LS, Fehrenbacher L, Moore MJ, Maroun JA, Ackland SP, Locker PK, Pirotta N, Elfring GL, Miller LL. Irinotecan plus fluorouracil and leucovorin for metastatic colorectal cancer. N Engl J Med 2000;343:905-14.

49. de Gramont A, Figer A, Seymour M, Homerin M, Hmissi A, Cassidy J, Boni C, Cortes-Funes H, Cervantes A, Freyer G, Papamichael D, Le Bail N, Louvet C, Hendler D, de Braud F, Wilson C, Morvan F, Bonetti A. Leucovorin and fluorouracil with or without oxaliplatin as first-line treatment in advanced colorectal cancer. J Clin Oncol 2000;18:293847.

50. Melichar B, Voboril Z, Cerman J, Melicharova K, Mergancova J, Voboril $\mathrm{R}$, Jandik P. Survival of patients with colorectal cancer liver metastases treated by regional chemotherapy. Hepatogastroenterology 2006;53:426-34.

51. Makela J, Kantola R, Tikkakoski T, Sinoluoto T, Leinonen S, Kiviniemi $\mathrm{H}$, Laitinen S, Kairaluoma M. Superselective intra-arterial chemotherapy with mitomycin $C$ in hepatic metastases from colorectal cancer. J Surg Oncol 1997;65:127-31.

52. Link KH, Pillasch J, Formentini A, Sunelaitis E, Leder G, Safi F, Kornmann M, Beger HG. Downstaging by regional chemotherapy of non-resectable isolated colorectal liver metastases. Eur J Surg Oncol 1999;25:381-8.

53. Kemeny N, Seiter K, Niedzwiecki D, Chapman D, Sigurdson E, Cohen A, Botet J, Oderman P, Murray P. A randomized trial of intrahepatic infusion of fluorodeoxyuridine with dexamethasone versus fluorodeoxyuridine alone in the treatment of metastatic colorectal cancer. Cancer 1992;69:327-34.

54. Kern W, Berckert B, Lang N, Stemmler J, Beykirch M, Stein J, Goecke E, Waggerhauser T, Braess J, Schalhorn A, Hiddemann W. Phase I and pharmacokinetic study of hepatic arterial infusion with oxaliplatin 
in combination with folinic acid and 5-fluorouracil in patients with hepatic metastases from colorectal cancer. Ann Oncol 2001;12:599603.

55. Del Freo A, Fiorentini G, Sanguinetti F, Muttini MP, Pennucci C, Mambrini A, Pacetti P, Della Seta R, Lombardi M, Torri T, Cantore $M$. Hepatic arterial chemotherapy with oxaliplatin, folinic acid and 5 -fluorouracil in pre-treated patients with liver metastases from colorectal cancer. In Vivo 2006;20:743-6.

56. Neyns B, van Nieuwenhove Y, Aerts M, Fontaine C, Vermeij J, Schallier D, Decoster L, De Mey J, Vandenbroucke f, Hoorens A, Delvaux G, De Greve J. Hepatic arterial infusion of oxaliplatin and L-folinic acidmodulated 5-fluorouracil for colorectal cancer liver metastases. Anticancer Res 2006;26:611-20.

57. Boige V, Malka D, Elias D, Castaing M, De Baere T, Goere D, Dromain C, Pocard M, Ducreux M. Hepatic arterial infusion of oxaliplatin and intravenous LV5FU2 in unresectable liver metastases from colorectal cancer after systemic chemotherapy failure. Ann Surg Oncol 2008; 15:219-26.

58. Mancuso A, Giuliani R, Accetura C, Palma M, D Auria G, Cecere F, Paoluzzi L, Bezzi M, Massidda B, Cortesi E. Hepatic arterial continuous infusion $(\mathrm{HACl})$ of oxaliplatin in patients with unresectable liver metastases from colorectal cancer. Anticancer Res 2003;23:1917-22.

59. Ducreux M, Ychou M, Laplanche A, Gamelin E, Lasser P, Husseini F, Quenet F, Viret F, Jacob JH, Boige V, Elias D, Delperro JR, Luboinski M. Hepatic arterial oxaliplatin infusion plus intravenous chemotherapy in colorectal cancer with inoperable hepatic metastases: a trial of the gastrointestinal group of the Federation Nationale des Centres de Lutte contre le Cancer. J Clin Oncol 2005;23:4881-7.

60. Fiorentini G, Rossi S, Dentico P, Meucci F, Bonechi F, Bernardeschi P, Cantore M, Guadagni S, De Simone M. Oxaliplatin hepatic arterial infusion chemotherapy for hepatic metastases from colorecta cancer: a phase I-Il clinical study. Anticancer Res 2004;24:2093-6.

61. Guthoff I, Lotspeich E, Fester C, Wallin I, Schatz M, Ehrsson H, Kornmann M. Hepatic artery infusion using oxaliplatin in combination with 5-fluorouracil, folinic acid and mitomycin C: Oxaliplatin pharmacokinetics and feasibility. Anticancer Res 2003;23:5203-8.

62. Carnaghi C, Santoro A, Rimassa L, Doci R, Rosati R, Pedicini V, Gullo G, Zuradelli M, Abbadessa G, Morenghi E, Marcon I, Garassino I. The efficacy of hybrid chemotherapy with intravenous oxaliplatin and folinic acid and intra-hepatic infusion of 5-fluorouracil in patients with colorectal liver metastases: a phase II study. Invest New Drugs 2007;25:479-85.

63. Seki H, Ozaki T, Shiina M. Hepatic arterial infusion chemotherapy using fluorouracil followed by systemic therapy using oxaliplatin plus fluorouracil and leucovorin for patients with unresectable liver metastases from colorectal cancer. Cardiovasc Intervent Radiol 2009;32:679-86.

64. Fiorentini G, Ricchi Lucchi S, Giovanis P, Cantore M, Guadagni S, Papiani G. Irinotecan hepatic arterial infusion chemotherapy for hepatic metastases from colorectal cancer: results of a phase I clinical study. Tumori 2001;87:388-90.

65. Melichar B, Dvorak J, Jandik P, Touskova M, Malirova E, Mergancova $J$, Voboril Z. Regional administration of irinotecan in combination with 5-fluorouracil and leucovorin in patients with colorectal cancer liver metastases - a pilot experience. Hepatogastroenterology 2001;48:1721-6.

66. Idelevich E, Greif F, Mavor E, Miller R, Kashtan H, Susmalian S, Ariche A, Brenner B, Baruch NB, Dinerman M, Shani A. Phase Il study of UFT with leucovorin plus hepatic arterial infusion with irinotecan, 5-fluorouracil and leucovorin for non-resectable liver metastases of colorectal cancer. Chemotherapy 2009;55:76-82.

67. van Riel JMGH, van Groeningen $C J$, Kedde MA, Gall H, Leisink MA, Gruia G, Pinedo HM, van der Vijgh WJF, Giaccome G. Continuous administration of irinotecan by hepatic arterial infusion: a phase I and pharmacokinetic study. Clin Cancer Res 2002;8:405-12.

68. Guichard S, Terret C, Hennebelle I, Lochon I, Chevreau P, Fretigny E, Selves J, Chatelut E, Bugat R, Canal P. CPT-11 converting carboxylesterase and topoisomerase I activities in tumour and normal colon and liver tissues. Br J Cancer 1999;80:364-70.

69. Martin RCG, Joshi J, Robbins K, Tomalty D, Bosnjakovik P, Derner M, Padr R, Rocek M, Scupchenko A, Tatum C. Hepatic intra-arterial injection of drug-eluting bead, irinotecan (DEBIRI) in unresectable colorectal liver metastases refractory to systemic chemotherapy: results of multi-institutional study. Ann Surg Oncol 2011;18:192-8.

70. Yamaguchi T, Matsumoto H, Yasutome M, Mori T, Takahashi K. Phase
I/II study of irinotecan, UFT and leucovorin with hepatic arterial infusion using 5-FU in colorectal cancer patients with unresectable liver metastases. Cancer Chemother Pharmacol 2011;67:629-35.

71. Gallagher DJ, Capanu M, Raggio G, Kemeny N. Hepatic arterial infusion plus systemic irinotecan in patients with unresectable hepatic metastases from colorectal cancer previously treated with systemic oxaliplatin: a retrospective analysis. Ann Oncol 2007;18:1995-9.

72. Bouchahda M, Adam R, Giacchetti S, Castaing D, Brezault-Bonnet C, Hauteville D, Innominato PF, Focan C, Machover D, Levi F. Rescue chemotherapy using multidrug chronomodulated hepatic arterial infusion for patients with heavily pretreated metastatic colorectal cancer. Cancer 2009;115:4990-9.

73. Chen YI, Yan Z, Wang J, Wang X, Luo J, Liu Q. Hepatic arterial infusion with oxaliplatin irinotecan and doxifluridine for unresectable liver metastases of colorectal cancer. Anticancer Res 2010;30:3045-50.

74. Khouri C, Guiu B, Cercueil JP, Chauffert B, Ladoire S, Ghiringhelli F. Raltitrexed and oxaliplatin hepatic arterial infusion for advanced colorectal cancer: a retrospective study. Anti-Cancer Drugs 2010;21:656-61.

75. van lersel LBJ, Verlaan MR, Vahrmeijer AL, van Persijin van Meerten EL, Tijl FGJ, Sparidans RW, Gelderblom H, Kuppen PJK, Tollenaar RAEM, van de Velde CJH. Hepatic artery infusion of high-dose melphalan at reduced flow during isolated hepatic perfusion for treatment of colorectal metastases confined to the liver: a clinical and pharmacologic evaluation. Eur J Surg Oncol 2007;33:874-81.

76. Fallik D, Ychou M, Jacob J, Colin P, Seitz JF, Baulieux J, Adenis A, Douillard JY, Couzigou P, Mahjoubi R, Ducreux M, Mahjoubi M, Rougier P. Hepatic arterial infusion using pirarubicin combined with systemic chemotherapy: a phase II study in patients with nonresectable liver metastases from colorectal cancer. Ann Oncol 2003;14:85663.

77. Hartmann JT, Schmoll E, Bokemeyer C, Fety R, Lucas C, Giroux B, Schmoll HJ. Phase I pharmacological study of intra-arterially infused fotemustine for colorectal liver metastases. Eur J Cancer 1998;34:8791.

78. Guiu B, Vincent J, Guiu S, Ladoire S, Ortega-Deballon P, Cercueil JP, Chauffert B, Ghiringhelli F. Hepatic arterial infusion of gemcitabine-oxaliplatin in a large metastasis from colon cancer. World J Gastroenterol 2010;16:1150-4.

79. Cunningham D, Hurnblet $Y$, Siena $S$, Khayat $D$, Bleiberg $H$, Santoro A, Bets D, Mueser M, Harstrick A, Verslype C, Chau I, Van Cutsem E. Cetuximab monotherapy and cetuximab plus irinotecan in irinotecan-refractory metastatic colorectal cancer. N Engl J Med 2004;351:337-45.

80. Van Cutsem $E$, Peeters $M$, Siena $S$, Humblet $Y$, Hendlisz A, Neyns $B$ Canon JL, Van Laethem JL, Maurel J, Richardson G, Wolf M, Amado RG. Open-label phase III trial of panitumumab plus best supportive care compared with best supportive care alone in patients with chemotherapy-refractory metastatic colorectal cancer. J Clin Oncol 2007;25:1658-64

81. Giantonio BJ, Catalano PJ, Meropol NJ, O'Dwyer PJ, Mitchell EP, Alberts SR, Schwartz MA. Bevacizumab in combination with oxaliplatin, fluorouracil, and leucovorin (FOLFOX4) for previously treated metastatic colorectal cancer: results from the Eastern Cooperative Oncology Group study E3200. J Clin Oncol 2007;25:1539-44.

82. Van Cutsem E, Kohne CH, Hitre E, Zaluski J, Chien CRC, Makhson A, D Haens G, Pinter T, Lim R, Bodoky G, Roh JK, Folprecht G, Ruff P, Stroh C, Tejpar S, Schlichting M, Nippgen J, Rougier P. Cetuximab and chemotherapy as initial treatment for metastatic colrectal cancer. $\mathrm{N}$ Engl J Med 2009;360:1408-17.

83. Neyns B, Aerts $M$, van Nieuwenhove $Y$, Fontaine $C$, de Coster $L$, Schallier D, Vanderauwera J, de Munck F, Vandenbroucke F, Everaert $\mathrm{H}$, Meert V, de Mey J, de Ridder M, Delvaux G, de Greve J. Cetuximab with hepatic arterial infusion for chemotherapy for the treatment of colorectal cancer liver metastases. Anticancer Res 2008;28:2459-68.

84. Camacho LH, Garcia S, Panchal AM, Lim J, Hong DS, Ng C, Madoff DC, Fu S, Gayed I, Kurzrock R. Exploratory study of hepatic arterial infusion oxaliplatin with systemic 5-fluorouracil/bevacizumab in patients with refractory solid tumor and extensive liver metastases. Clin Colorectal Cancer 2010;9:311-4.

85. Kemeny NE, Jarnagin WR, Capanu M, Fong Y, Gerwitz AN, DeMatteo RP, DAngelica MI. Randomized phase II trial of adjuvant hepatic arterial infusion and systemic chemotherapy with or without bevacizumab in patients with resected hepatic metastases from colorectal cancer. J Clin Oncol 2011;29:884-9. 
86. Tsimberidou AM, Fu S, Ng C, Lim JA, Wen S, Hong D, Wheler J, Bedikian AY, Eng C, Wallace M, Camacho LH, Kurzrock R. A phase 1 study of hepaptic arterial infusion of oxaliplatin in combination with systemic 5-fluorouracil, leucovorin, and bevacizumab in patients with advanced solid tumors metastatic to the liver. Cancer 2010;116:4086-94.

87. Ribero D, Wang H, Donadon M, Zorzi D, Thomas MB, Eng C, Chang DZ, Curcley SA, Abdalla EK, Ellis LM, Vauthey JN. Bevacizumab improves pathologic response and protects against hepatic injury in patients treated with oxaliplatin-based chemotherapy for colorectal liver metastases. Cancer 2007;110:2761-77.

88. Bouchahda M, Levi F, Adam R, Rougier P. Modern insights into hepatic arterial infusion for liver metastases from colorectal cancer. Eur J Cancer 2011;47:2681-90.

89. Goere D, Deshaies I, de Baere T, Boige V, Malka D, Dumont F, Dromain C, Ducreux M, Elias D. Prolonged survival of initially unresectable hepatic colorectal cancer patients treated with hepatic arterial infusion of oxaliplatin followed by radical surgery of metastases. Ann Surg 2010;251:686-91.

90. Ganeshan A, Upponi S, Hon L, Warakaulle D, Beroi R. Hepatic arterial infusion of chemotherapy: the role of diagnostic and interventional radiology. Ann Oncol 2008;19:847-51.

91. Hildebrandt B, Pech M, Nicolaou A, Langrehr JM, Kurcz J, Bartels B, Miersch A, Felix R, Neuhaus P, Riess H, Dorken B, Ricke J. Interventionally implanted port catheter systems for hepatic arterial infusion of chemotherapy in patients with colorectal liver metastases: A phase II-study and historical comparison with the surgical approach. BMC Cancer 2007;7:69.

92. Arisawa Y, Sutanto-Ward E, Fortunato L, Sigurdson ER. Hepatic artery dexamethasone infusion inhibits colorectal hepatic metastases: a regional antiangiogenic therapy. Ann Surg Oncol 1995;2:114-20.

93. Rubbia-Brandt L, Audard V, Sartoretti P, Roth AD, Brezault C, Le Charpentier M, Dousset B, Morel P, Soubrane O, Chaussade S, Mentha G, Terris B. Severe hepatic sinusoidal obstruction associated with oxaliplatin-based chemotherapy in patients with metastatic colorectal cancer. Ann Oncol 2004;15:460-6.

94. Arotcarena R, Cales V, Berthelemy P, Parent $Y$, Malet M, Etcharry F, Ferrari S, Pariente A. Severe sinusoidal lesions: a serious and overlooked complication of oxaliplatin-containing chemotherapy? Gastroenterol Clin Biol 2006;30:1313-6.

95. Zorzi D, Lauren A, Pawlik TM, Lauwers GY, Vauthey JN, Abdalla EK. Chemotherapy-associated hepatotoxicity and surgery for colorectal liver metastases. Br J Surg 2007;94:274-86.

96. Melichar B, Dvorak J, Hyspler R, Zadak Z. Intestinal permeability in the assessment of intestinal toxicity of cytotoxic agents. Chemotherapy 2005;51:336-8.

97. Melichar B, Nemcová I. Eye complications of cetuximab therapy. Eur J Cancer Care 2007;16:439-43.

98. Melichar B, Touskova M, Solichova D, Kralickova P, Kopecky O. CD4+ T-lymphocytopenia and systemic immune activation in patients with primary and secondary liver tumours. Scand J Clin Lab Inv 2001;61:363-70.

99. Melichar B, Solichova D, Melicharova K, Malirova E, Cermanova M, Zadak Z. Urinary neopterin in patients with advanced colorectal carcinoma. Int J Biol Markers 2006;21:190-8.

100. Fraker DL, Soulen M. Regional therapy of hepatic metastases. Hem Oncol Clin N Am 2002;16:947-67.

101. Fong Y, Cohen AM, Fortner JG, Enker WE, Turnbull AD, Coit DG, Marrero AM, Prasad M, Blumgart LH, Brennan MF. Liver resection for colorectal metastases. J Clin Oncol 1997;15:938-46.
102. Kemeny N, Huang Y, Cohen AM, Shi W, Conti JA, Brennan MF, Bertion JR, Turnbull ADM, Sullivan D, Stockman J, Blumgart LH, Fong Y. Hepatic arterial infusion of chemotherapy after resection of hepatic metastases from colorectal cancer. N Engl J Med 1999;341:2039-48.

103. Kemeny MM, Adak S, Gray B, Macdonald JS, Smith T, Lipsitz S, Sigurdson ER, O`Dwyer PJ, Benson AB. Combined-modality treatment for resectable metastatic colorectal carcinoma to the liver: surgical resection of hepatic metastases in combination with continuous infusion of chemotherapy - an Intergroup study. J Clin Oncol 2002;20:1499-505.

104. Lorenz M, Muller HH, Schramm H, Gassel HJ, Rau HG, Ridwelski K Hauss J, Stieger R, Jauch KW, Bechstein WO, Encke A. Randomized trial of surgery versus surgery followed by adjuvant hepatic arterial infusion with 5-fluorouracil and folinic acid for liver metastases of colorectal cancer. Ann Surg 1998;228:756-62.

105. Kemeny N, Jarnagin W, Gonen M, Stockman J, Blumgart L, Sperber D, Hummer A, Fong Y. Phase I/II study of hepatic arterial therapy with floxuridine and dexamethasone in combination with intravenous irinotecan as adjuvant treatment after resection of hepatic metastases from colorectal cancer. J Clin Oncol 2003;21:3303-9.

106. Markman M, Liu PY, Wilczynski S, Monk B, Copeland LJ, Alvarez RD, Jiang C, Alberts D. Phase III randomized trial of 12 versus 3 months of maintenance paclitaxel in patients with advanced ovarian cancer after complete response to platinum and paclitaxel-based chemotherapy: a Southwest Oncology Group and Gynecologic Oncology Group trial. J Clin Oncol 2003;21:2460-5.

107. Clancy TE, Dixon E, Perlis R, Sutherland FR, Zinner MJ. Hepatic arterial infusion after curative resection of colorectal cancer metastases: a meta-analysis of prospective clinical trials. J Gastrointest Surg 2005;9:198-206.

108. Wieser M, Sauerland S, Arnold D, Schmiegel W, Reinacher-Schick A. Peri-operative chemotherapy for the treatment of resectable liver metastases from colorectal cancer: a systemic review and metaanalysis of randomized trials. BMC Cancer 2010;10:309.

109. Leonard GD, Brenner B, N.E. K. Neoadjuvant chemotherapy before liver resection for patients with unresectable liver metastases from colorectal carcinoma. J Clin Oncol 2005;23:2038-48.

110. Kemeny NE, Melendez HFD, Capanu M, Paty PB, Fong Y, Schwartz LH, Jarnagin WR, Patel D, DAngelica M. Conversion to resectability using hepatic artery infusion plus systemic chemotherapy for the treatment of unresectable liver metastases from colorectal carcinoma. J Clin Oncol 2009;27:3465-71.

111. Martin RCG, Scoggins CR, McMasters KM. A phase II study of radiofrequency ablation of unresectable metastatic colorectal cancer with hepatic arterial infusion pump chemotherapy. J Surg Oncol 2006;93:387-93.

112. Xu J, Zhong Y, Weixin N, Xinyu Q, Yanhan L, Li R, Jianhua W, Zhiping $Y$, Jiemin C. Preoperative hepatic and regional arterial chemotherapy in the prevention of liver metastasis after colorectal cancer surgery. Ann Surg 2007;245:583-90:

113. Tang JT, Wang JL, Fang JY. Meta-analysis: perioperative regional liver chemotherapy for improving survival and preventing liver metastases in patients with colorectal carcinoma. J Dig Dis 2010;11:208-14.

114. Kemeny N. In defense of hepatic arterial infusion for hepatic metastases of colorectal cancer. J Natl Compr Cancer Netw 2010;8:507-9.

115. Nishiofuku H, Tanaka T, Aramaki T, Boku N, Inaba Y, Sato Y, Matsuoka M, Otsuji T, Y. A, Kichikawa K. Hepatic arterial infusion of 5-fluorouracil for patients with liver metastases from colorectal cancer refractory to standard systemic chemotherapy: a multicenter, retrospective analysis. Clin Colorectal Cancer 2010;9:305-10. 